\title{
Injury Prevention Implications in an Ethnically Mixed Population: A Study of 764 Patients with Traumatic Brain Injury
}

\author{
Ashok Parchani, Kimball I Maull, Nissar Sheikh, Mark Sebastian
}

\section{ABSTRACT}

Objective: We hypothesized that an analysis of the demographic profile of patients who suffered moderate and severe traumatic brain injury ( $\mathrm{TBI}$ ) would identify wide variation in injury mechanism by age and ethnicity. The objective is to utilize this data to target injury prevention programs for specific population.

Methods: All head injured patients admitted to the trauma ICU were studied ( $N=764)$. Standard demographic data, nationality, and mechanism of injury were determined. All patients had moderate to severe TBI. Demographics were cross referenced with injury mechanism, nationality and age of exposure.

Results: Head injuries were more common in males, the expatriate population, and the age group from 21 to 40 years. Motor vehicle collision (MVC) was the most common injury mechanism followed by fall from height (FFH) with profound ethnic differences in both ages affected and populations at risk. Struck by falling objects (SFO) was the third most common injury mechanism. TBI mortality improved over the period of study, declining from 21 to $17 \%$.

Conclusion: Prevention or reduction in TBI severity has profound implications for improving public health and reducing TBI-related health care costs. The defining of populations at risk by nationality, injury mechanism and peak age of exposure can provide a model for coordinated regional or national injury prevention programs.

Keywords: Traumatic brain injury, Prevention, Demographics, Trauma, Fall, Rehabilitation.

How to cite this article: Parchani A, Maull KI, Sheikh N, Sebastian M. Injury Prevention Implications in an Ethnically Mixed Population: A Study of 764 Patients with Traumatic Brain Injury. Panam J Trauma Critical Care Emerg Surg 2012; $1(1): 27-32$.

Source of support: Nil

Conflict of interest: None declared

\section{RESUMEN}

Objetivos: Se hipotizó que un análisis del perfil demográfico de pacientes que sufrieron trauma encéfalocraneano (TEC) entre moderado y severo, tendrían una amplia variación en el mecanismo lesional, edades y étnicos. El objetivo es utilizar estos datos y dirigirlos hacia programas de prevención de traumatismos en poblaciones específicas.

Métodos: Todos los pacientes hospitalizados con TEC en la Unidad de Cuidados Críticos en Trauma fueron estudiados $(\mathrm{N}=764)$. Se registraron datos demográficos, nacionalidad y mecanismos traumáticos. Todos los pacientes presentaron TEC entre moderado y severo. Los datos demográficos se cotejaron con el mecanismo traumático, la nacionalidad y la edad al momento de la lesión.
Resultados: Los TEC fueron más frecuentes en hombres, la población de extranjeros y el grupo de edades entre los 21 - 40 años. La colisión por vehículo a motor (CVM) fue el mecanismo traumático más frecuente, seguido de las caídas desde la altura (CA). Hubieron marcadas diferencias étnicas tanto en las edades como en la población de riesgo. Lesiones por impacto de objetos contundentes representaron la tercera causa en frecuencia. La mortalidad por TEC mejoró durante el periodo de estudio, disminuyendo de 21 a $17 \%$.

Conclusiones: La prevención o reducción de la gravedad del TEC tiene importantes implicancias para mejorar la salud pública y reducir los costos de la atención relacionada con esa enfermedad. Al definir la población de riesgo por nacionalidad, mecanismo traumático y pico de edad de exposición, se provee un modelo regional o nacional coordinado para los programas de prevención de traumatismos.

Palabras clave: TEC, prevención, demográficos, trauma, caída, rehabilitación.

\section{INTRODUCTION}

In Qatar, head injury is major cause of morbidity and mortality both among Qatari citizens and expatriates. This may be attributed to rapid economic growth and the attendant construction boom seen in Qatar. High rise buildings in the city center, large industrial factories and the infrastructure required to support them are simultaneously under development. The close proximity of the projects and the expanding network of roads have created a large area of contiguous and continuous construction activity. The vigorous local economy has attracted large numbers of expatriate workers, expanding population density, and the relative wealth of this young country has led to dramatic increases in the number of motor vehicles on the road.

Demographically, Qatar is a young country. According to recent census data, a mere $1.5 \%$ of the population is over 65 years of age. The expatriate population is expanding rapidly and consists of active, working young persons. It is this young group that is most prone to head injuries.

Hamad General Hospital (HGH) is the only tertiary care referral center for the entire country. All patients with significant injuries, including TBI, are referred for treatment to HGH. The other three hospitals are secondary in nature, two of them being privately managed hospitals. An analysis of HGH data, therefore, reflects an analysis of the national experience with moderate-to-severe TBI.

Such an analysis could be useful to channel governmental resources for injury prevention. Prevention is the single most 
effective way to reduce the devastating loss of productivity TBI causes in the young, and prevent the prolonged intensive care unit stays and poor overall recovery in the elderly who suffer TBI.

\section{PATIENTS AND METHODS}

This is a retrospective hospital-based study of all injured patients with moderate-to-severe TBI admitted to the modern 24 bed surgical/trauma Intensive Care Unit at Hamad General Hospital, Doha, Qatar from January 2004 through December, 2008. The severity of neurologic impairment was defined by Glasgow Coma Scale (GCS) as moderate (GCS 9-12) and severe (GCS 3-8). There were 764 patients included in the study. Informal analyses had previously suggested an increasing incidence of severe TBI in younger patients and also in the elderly. Patient demographics and common mechanisms of injury were sought. The study was approved by the Hamad Institutional Review Board (IRB). All the data were collected from patient medical records. All patients were cared for using an aggressive head injury protocol which emphasized early injury detection, rapid initial resuscitation, avoidance of hypotension and hypoxia, and maintenance of cerebral perfusion with early intracranial monitoring. ${ }^{1}$ Demographic data included age, gender, nationality, and mechanism of injury, yearly distribution of incidence and prevalence and trends in mortality rates.

\section{RESULTS}

All data was extracted from medical records by the principal investigator (AP) and was complete in all cases. There was a gradual increase in the number of TBI patients admitted each year during the study period. All the TBI sustained were unintentional. Except for year 2007 when there was a slight decline in TBI from MVC, the increase has been sustained from both MVC and FFH-related causes. The slight fall in MVC-related TBI in 2007 may be attributed to new traffic rules and regulations imposed with stiff penalties for violations. If so, the effect was transient. The inexorable rise of head injuries due to FFH may be attributed to an increase in construction of high rise buildings (Fig. 1). There were 715 men (94\%) and 49 women (6\%) included in the study.

\section{Age}

Age ranged from 14 to 74 years with the heaviest clinical burden occurring during the productive year's age 21 through 40 (Table 1). However, $18 \%$ was seen among those less than 20 years, and also a surprising rate of $6 \%$ was seen among the elderly group 61 to 80 years. There were significant differences in peak age incidence when compared with both mechanism of injury and nationality.

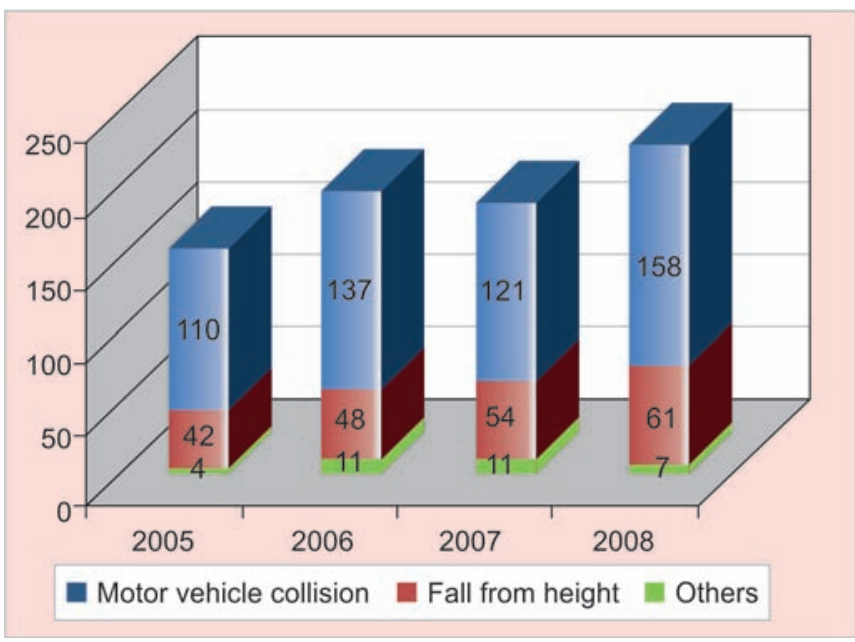

Fig. 1: Trends in TBI by etiology during study period

\begin{tabular}{|cccc|}
\hline \multicolumn{4}{|c|}{ Table 1: Age of occurrence of TBI in study group } \\
\hline Age group & Number & Percentage & Ratio \\
\hline $0-20$ & 134 & 17.53 & 0.17 \\
$21-40$ & 412 & 53.92 & 0.54 \\
$41-60$ & 170 & 22.25 & 0.22 \\
$61-80$ & 48 & 6.28 & 0.06 \\
\hline
\end{tabular}

\section{Mechanism of Injury}

The most common mechanisms of injury were motor vehicle crash (MVC), fall from height (defined as distance greater than 3 meters), and struck by falling object. Other mechanisms, including violent assault, were of minimal contribution. MVC accounted for 526 cases (69\%), fall from height 205 cases (27\%), and 23 persons were struck by heavy object (3\%). There were 10 assaults, accounting for approximately $1 \%$ of cases (Fig. 2).

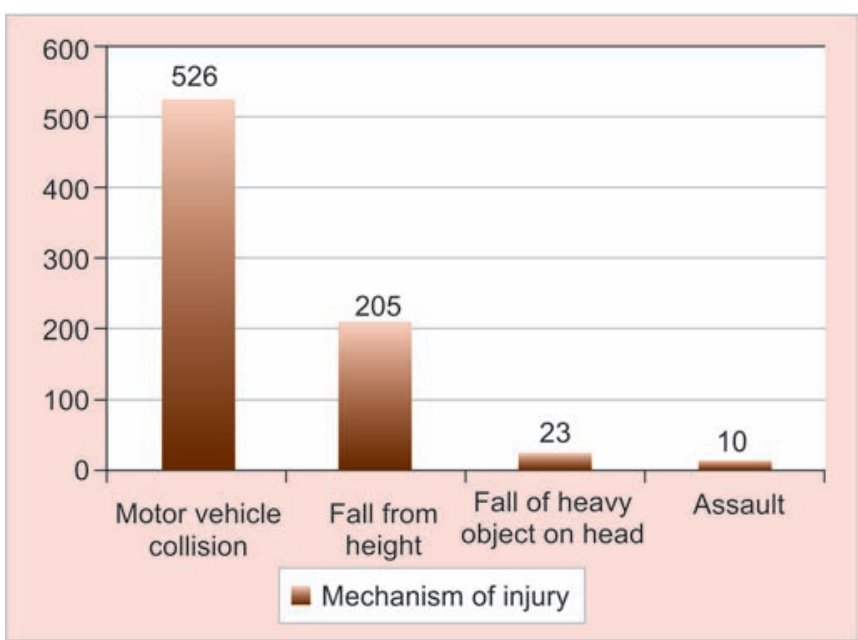

Fig. 2: Mechanisms of injury in 764 patients with TBI total of 4 years 
Injury Prevention Implications in an Ethnically Mixed Population: A Study of 764 Patients with Traumatic Brain Injury

\section{Nationality}

Of the 764 patients with TBI, $21 \%$ occurred in the local population compared to $79 \%$ in the expatriate population. This marked disparity of affected ethnic population was even more revealing when contrasted with injury mechanism. Although MVC was the most common mechanism of injury in both the local and expatriate populations, the expatriate population was at far greater risk of sustaining TBI in a fall from height (94\%) or being struck by falling object (100\%) (Fig. 3).

\section{Mechanism of Injury in Relation to Age}

Motor vehicle-related head injuries were seen in all age groups. The most common age group was between 21 and 40 years, (48\%) followed by less than 20 years age group $(20 \%)$ and 41 to 60 years group $(20 \%)$. Motor vehicle related head injuries were also seen in those 61 to 80 years (5\%). Head injuries due to falls from height peaked in the 21 to 40 age groups (58\%), but also affected the elderly (8\%). Fall of heavy object causing head injuries was seen mostly in working age group 21 to 40 years (78\%) (Table 2).
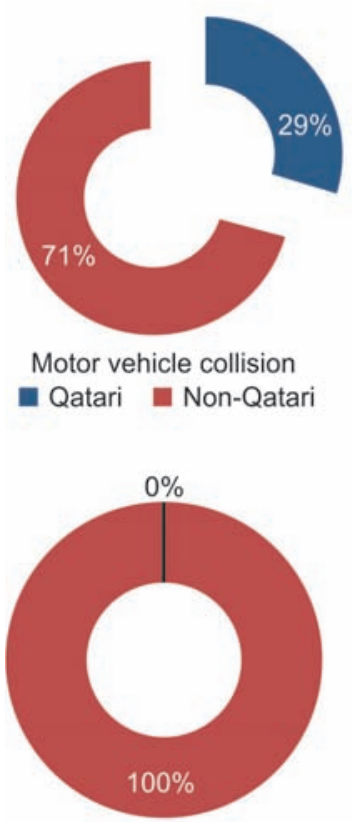

Heavy object on head

- Qatari Non-Qatari
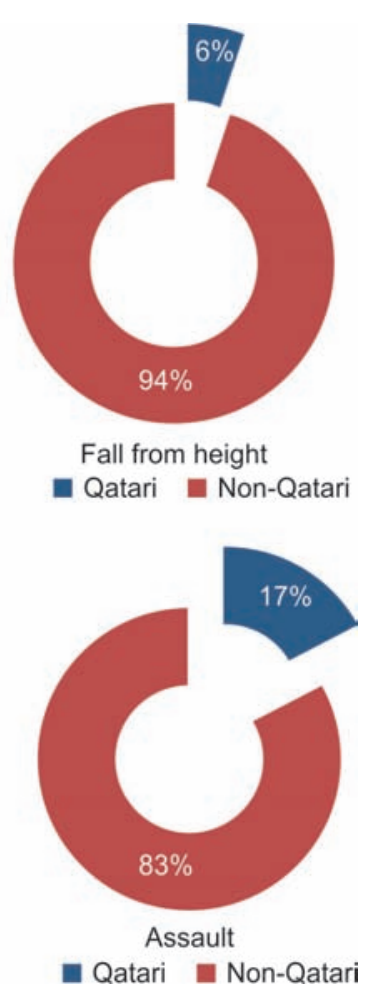

Fig. 3: Comparison of local and expatriate TBI patients by injury mechanism

Table 2: Mechanism of injury related to patient age

\begin{tabular}{lrrrr} 
Mechanism of injury & $\begin{array}{r}0-20 \\
\text { yrs }\end{array}$ & $\begin{array}{r}21-40 \\
\text { yrs }\end{array}$ & $\begin{array}{r}41-60 \\
\text { yrs }\end{array}$ & $\begin{array}{r}61-80 \\
\text { yrs }\end{array}$ \\
\hline MV collision & 111 & 272 & 112 & 31 \\
FFH & 22 & 119 & 48 & 16 \\
Heavy object on head & 1 & 18 & 3 & 1 \\
Assault & - & 3 & 7 & -
\end{tabular}

\section{Mechanism of Injury in Relation to Age and Nationality}

There were significant differences in age affected when nationality and injury mechanism were considered together. For example, mean age seen in the patients sustaining head injuries due to MVC was 38 years for the expatriate group compared to 22 years for the local population. Mean age of head injured patients due to falls was 30 years in the expatriate group vs 64 years for the local population. These striking differences are depicted in Figures $4 \mathrm{~A}$ and $\mathrm{B}$.

\section{Mortality}

There were 144 deaths during the 4-year period of the study for a mortality rate of $19 \%$. Figure 5 shows the deaths according to mechanism of injury and a decreasing mortality from $21 \%$ in 2006 to $17 \%$ in 2008 is confirmed in Figure 6.

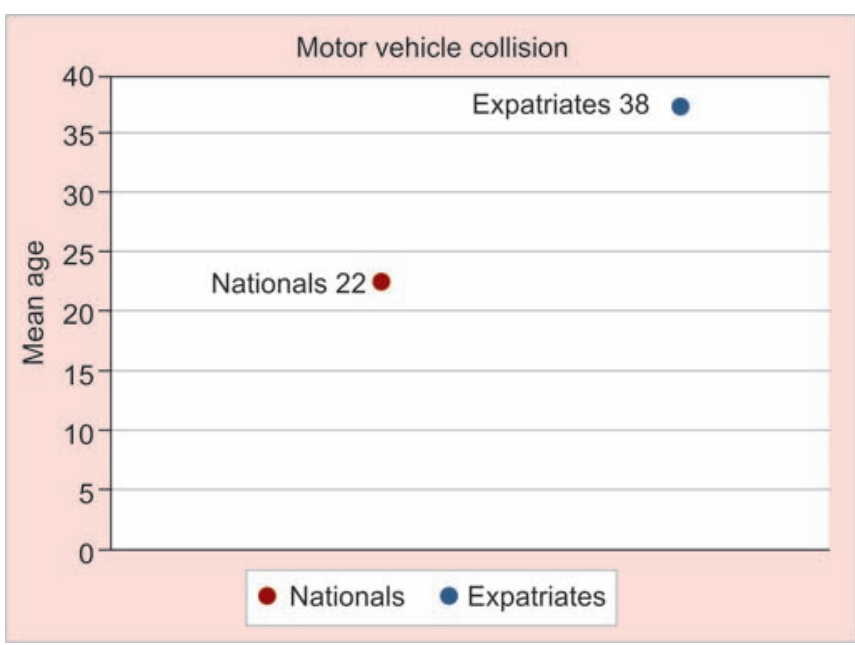

Fig. 4A: Mean age differences by nationality in TBI caused by motor vehicle collision

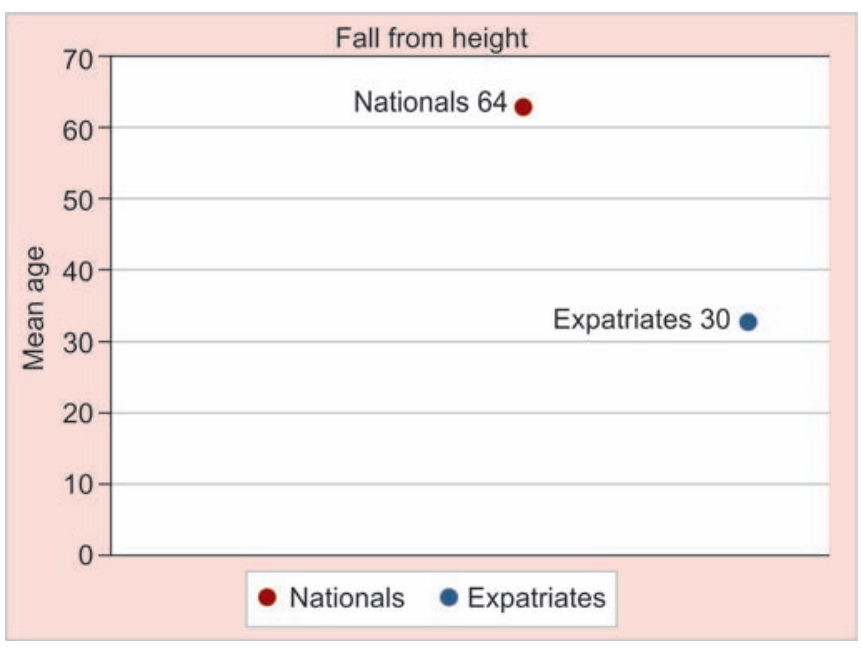

Fig. 4B: Mean age differences by nationality in TBI caused by falls from height 


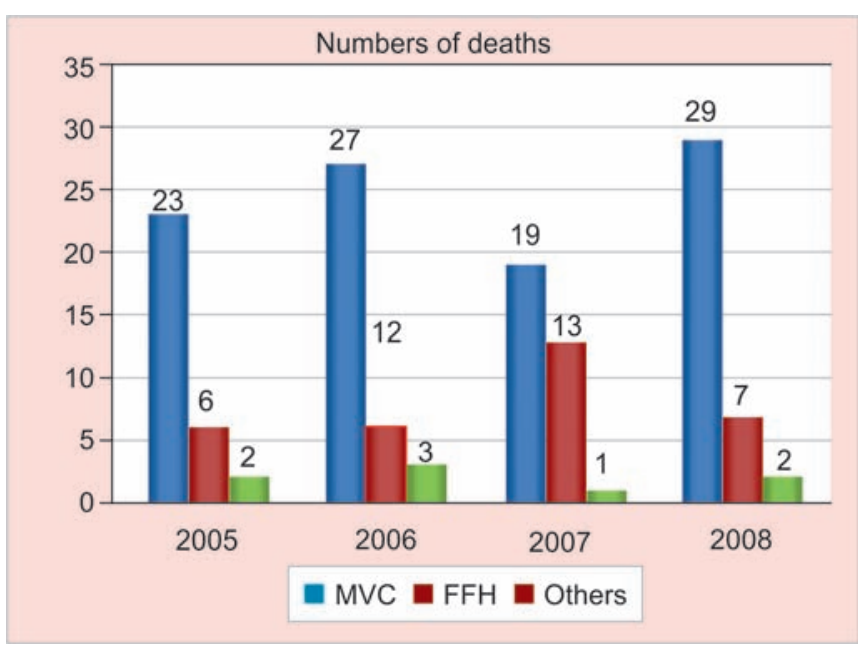

Fig. 5: Head injury deaths by mechanism of injury during the study period

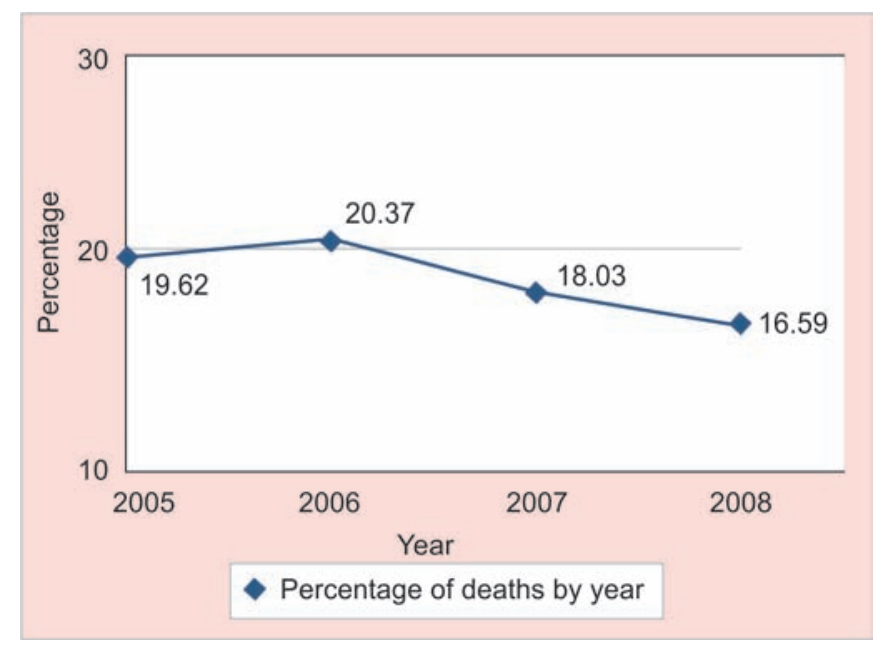

Fig. 6: Trends in mortality rates over the course of the study

\section{DISCUSSION}

Injury prevention, to be effective, must focus on populations at risk. The current study reviewed 764 patients with head trauma injured seriously enough to require admission to an intensive care unit. All patients had moderate to severe TBI which was the common factor among the study group. However, a closer investigation of these patients showed wide variation by age, by nationality (Qatari vs non-Qatari) and by mechanism of injury. The overall mortality rate of $19 \%$ emphasizes the severity of injury in the study group. The fall in mortality may be related to improvements in prehospital transportation, the establishment of a dedicated trauma service, and/or improvements in critical care.

Since, even moderate TBI can lead to long-term cognitive impairment and an inability to return to the workforce, prevention of the injury or reduction in the severity of the head injury can reduce health care costs and improve outcome.
Traumatic brain injury was more common in the expatriate population regardless of injury mechanism. This is not surprising since, the native population make-up approximately $20 \%$ of the inhabitants. The injured were typically unrestrained drivers or passengers or they were pedestrians. Qatar has high incidence of head injuries due to vehicular crashes. Studies have shown that in the Gulf States, deaths due to motor vehicle collisions are second only to infectious diseases as a cause of death. ${ }^{2}$ A significant finding was the low rate of seat belt use, especially among young Qataris. Our own data puts seat belt use at $27 \%$ among inpatients on the trauma service. It is clear that efforts to reduce vehicular crashes and their severity can favorably affect these head injury statistics. Whether directed at speeding, safety restraint use, alcohol use (a minimally contributory factor in Qatar), or focused on improvements in trauma care through systems development, injury prevention must be adapted to the populations at risk.

Falls were the next most important cause of TBI. However, the demographics point out that this is almost exclusively an expatriate problem except for elderly natives. The average age was 30 years among the expatriate population and 64 years among the local population. These injuries were occupation related for the expatriate group. Results show that more than $95 \%$ of cases of head injuries due to fall from height occurred at the site of work involving expatriate workers largely from the Asian subcontinent. Most of these workers emigrated from small villages, were poorly educated and not familiar with construction safety procedures. Unfamiliarity with working in high rise buildings and working at extremes of temperature combined to increase injury risk. Because these expatriates come from such disparate cultures as Nepal, Sri Lanka, Bangladesh, Philippines, Vietnam and others, the program on occupational safety must be multilingual and provided in their respective languages before they are exposed to working sites so that they may understand and follow these safety measures while working.

The mechanism of being struck by falling objects is exclusively a jobsite injury. The use of barriers along upper construction floors serves the dual purpose of decreasing falls and restricting objects from falling on workers below. Hard hats clearly offer some protection but must be worn to be effective.

Huge costs are incurred in caring for patients who require ICU services especially those with head injuries, as management of these patients requires advanced monitoring and labor intensive clinical care. ${ }^{3,4}$ Foreign workers with severe head injury also tend to remain longer in the ICU due to repatriation issues, compensation claims and lack of family contacts. 
Falls in the elderly, while of similar mechanism make-up a very different injury population. In the elderly, fall-related head injuries may be due to cognitive impairment, or as a side effect of various medications such antihypertensive, psychotropic drugs and anticoagulants. ${ }^{5,6}$ Falls can also arise from environmental hazards, such as lack of safety features, worn out carpets on stairways, slippery surfaces, or as a result of the aging process itself. ${ }^{7,8}$ Studies have shown that with increasing age there is a higher mortality due to fall-related head injury. ${ }^{9,10}$ With the increasing elderly population, appropriate family education and environmental protection (home safety programs) can reduce the incidence of injuries in the elderly.

In addition to the cost of providing intensive care, the social impact of admissions to ICU and the prolonged stay of these patients have a profound effect on families. ${ }^{11} \mathrm{~A}$ sudden, unexpected admission to the ICU and uncertainty of prognosis is highly stressful. Many studies show that these families need strong social support, part of which is a truthful assessment of the initial injury, and consistent updates about the patient's condition by the physicians in charge of the patient's care. ${ }^{12-17}$

The long-term effects of head injuries are quite serious, with many of the social and emotional costs impossible to estimate. The disabilities which arise from head injuries remain for many years and affect the patient's ability to work and interact within society. Most of the serious head injured patients develop long-term motor, sensory and psychological disabilities and are in need of long-term rehabilitation, which may affect their social life and family relations. ${ }^{18,19}$

In addition to psychological and behavior problems, physical symptoms, such as gait disturbance, extremity contractures, impaired balance, incontinence, and inability to care for themselves leads to lack of confidence, impaired self esteem, anxiety and frustration..$^{20}$ Head injury not only has impact on the patient, but more often than not leads to significant change in the lives of the family. The families so affected need long-term social and emotional support to cope with the disruptions caused by head injury. Reactive depression is manifest in more than half of the families with a traumatically brain injured member. ${ }^{21}$

\section{CONCLUSION AND RECOMMENDATIONS}

This study shows that the expatriate population is at greatest risk of head injuries regardless of injury mechanism. Based on current demographics and population figures, the local population was over-represented in head injuries caused by motor vehicle collisions. The local elderly population is at particular risk of head injuries due to falls from height. Although the expatriate population accounted for the majority of TBI by all mechanisms, trends indicated injury prevention could be significant in the MVC group for young Qataris, the fall from height group for elderly Qatari citizens, and in the fall from height/struck by heavy object group for expatriates of working age.

Since head injuries are preventable, targeting of high risks group through public awareness and injury prevention programs can be expected to reduce this trauma burden. Awareness programs begin in the schools. Those taking care of the elderly can be taught home safety and fall prevention measures by the primary physicians and nursing staff when this patient group visits their clinics. Foreign workers should be educated on the dangers of working in high rise buildings, safety measures and safety equipment should be legislatively mandated and enforced, and the capacity for postinjury rehabilitation should be expanded.

Head injuries leave devastating effects not only on the patient but also on their families and add a heavy cost to society. After overcoming the initial physical injury, the psychological, social and emotional difficulties that follow often exert lifelong challenges to the quality of life of the family.

\section{REFERENCES}

1. Bullock R, Chestnut RM, Clifton G. Guidelines for the management of severe head injury. Brain Trauma Foundation. J Neurotrauma 1996;13:639-734.

2. AL-Tukhi MH. Road traffic accidents and data comprising Gulf countries and Riyadh area. Proceedings of a symposium on multiple trauma in road accidents. Annals of Saudi Medicine 1988;8:310.

3. Matz PG, Pitts L. Monitoring in traumatic brain injury. Clin Neurosurg 1997;44:267-94.

4. Sheinberg M, Kanter MJ, Robertson CS. Continuous monitoring of jugular venous oxygen saturation in head-injured patients. J Neurosurg 1992;76:212-17.

5. Thapa PB, Gideon P. Psychotropic drugs and risk of recurrent falls in ambulatory nursing home residents. Am J Epidemiology 1995;142:202-11.

6. Luukinen H, Viramo P, Koski K. Head injuries and cognitive decline among older adults: A population-based study. Neurology 1999;52:557-562

7. Bell AJ, Talbot-Stern JK, Hennessy A. Characteristics and outcomes of older patients presenting in the emergency department after a fall: A retrospective analysis. Med J Aus 2000;173:179-82.

8. Herndon JG, Helmick CG, Sattin RW. Chronic medical conditions and risk of fall injury events at home in older adults. J Am Geriatr Soc 1997;45:739-43.

9. Cifu DX. Functional outcomes of older adults with TBI: A prospective, multicenter analysis. Arch Phys Med Rehabil 1996, 77:883-88.

10. Englander J Cifu DX. The older adult with traumatic brain injury. In: Rehabilitation of the adult and child with traumatic brain injury FA Davis (Ed). Philadelphia 1999;453-71.

11. Barker FG. Traumatic brain injury. In: Principles of neuroepidemiology. Batchelor T, Cudkowics ME (Eds). Boston, Butterworth Heinemann, 2001. 
12. Bond AE, Draeger CR, Mandleco B. Needs of family members of patients with severe traumatic brain injury-implications for evidenced - based practice. Crit Care Nurse 2003;23:63-72.

13. Wilkinson P. A qualitative study to establish the self-perceived needs of family members of patients in a general intensive care unit. Intensive Crit Care Nurs 1995;11;77-86.

14. Engli M, Kirsivali-Farmer K. Needs of family members of critically ill patients with and without acute brain injury. J Neurosci Nurs 1993;25;78-85.

15. Hayes E. Needs of family members of critically ill patients - A Northern Ireland perspective. Intensive Care Nurs 1990;6:25-29.

16. Jamerson PA, Scheibmeir M, Bott MJ. The experiences of family with a relative in the intensive care unit. Heart Lung 1996; 25:467-77.

17. Maitz EA, Sachs P. Treating families of individuals with traumatic brain injury from a family systems perspective. Head Trauma Rehabil 1995;10:1-11.

18. Martin K. Loss without death. A dilemma for the head-injured patient's family. J Neurosci Nurs 1994;26:134-39.

19. Witol AD, Sander AM, Kreutzer. A longitudinal analysis of family needs following traumatic brain injury. Neurorehabilitation 1996;7:175-87.

20. Hemingway S, McAndrew S. Acquired brain injury_-identifying emotional and cognitive needs. Nursing Standard 1997;12:40-46.
21. Gillen R. Distress, depressive symptoms and depressive disorder among caregivers of patients with brain injury. Journal of Traumatic Brain Rehabilitation 1998;13:88-110.

\section{ABOUT THE AUTHORS}

\section{Ashok Parchani (Corresponding Author)}

Trauma Critical Care Service, Department of Surgery, Hamad General Hospital, Doha, Qatar, e-mail: aparchani@yahoo.com

\section{Kimball I Maull}

Adjunct Professor, Department of Surgery, University of Pittsburgh Medical Center, PA, USA

\section{Nissar Sheikh}

Surgical Intensive Care Unit, Department of Anesthesia, Hamad General Hospital, Doha, Qatar

\section{Mark Sebastian}

Trauma Critical Care Service, Department of Surgery, Hamad General Hospital, Doha, Qatar 